\section{Estudo \\ CoDebate}

em Cestão

Plamejamento
Revista Estudo \& Debate, Lajeado, v. 27, n. 2, 2020. ISSN 1983-036X

DOI: http://dx.doi.org/10.22410/issn.1983-036X.v27i2a2020.2547

\title{
DINÂMICAS TERRITORIAIS DOS RESÍDUOS ELETROELETRÔNICOS DOMICILIARES NA CIDADE DE MATINHOS-PR
}

\author{
Alexandre Dullius ${ }^{1}$, Maclovia Corrêa da Silva ${ }^{2}$
}

\begin{abstract}
Resumo: Este artigo trata das dinâmicas territoriais dos resíduos eletroeletrônicos domiciliares na cidade de Matinhos-PR. Trata-se de uma cidade localizada no litoral paranaense, que possui áreas de preservação ambiental na Mata Atlântica. Possui um sistema de coleta de resíduos sólidos urbanos dirigida pelo Plano de Gerenciamento Integrado dos Resíduos Sólidos e conta com duas associaçóes de catadores e uma organização náo-governamental para coletar, separar e comercializar os materiais reutilizáveis e recicláveis. O objetivo deste artigo é analisar aspectos das dinâmicas territoriais da coleta e disposiçáo de resíduos eletroeletrônicos que acontecem num espaço social multifacetado em que os atores trabalham com o consentimento, com a desigualdade, e com a dominaçáo. Trata-se de uma pesquisa qualitativa, com o uso de ferramentas metodologias das entrevistas, observaçóes e visitas técnicas. A participação dos poderes públicos para a organizaçáo da coleta e destino dos resíduos eletroeletrônicos tem sido relevante, no sentido de criação de políticas, leis e decretos. Porém, ainda falta sincronia entre os atores que participam do processo, desde a indústria, até os coletores e consumidores. Conclui-se que nem todos podem construir e modelar o processo de coleta e disposiçâo dos resíduos sólidos, porque existem hierarquias quanto ao acesso aos recursos e às informações que causa indesejáveis situaçóes de dependência.
\end{abstract}

Palavras-chave: território, resíduos eletroeletrônicos domiciliares; associações de materiais recicláveis; Associação Fukuoka Instituto.

1 Mestre em Bioenergia pela Universidade Federal do Paraná - UFPR. Doutorando do Programa de Pós graduação em Tecnologia da Universidade Tecnológica Federal do Paraná. Docente do Instituto Federal do Paraná, Campus Paranaguá.

2 Professora titular da Universidade Tecnológica Federal do Paraná - UTFPR. Mestrado em História do Brasil pela Universidade Federal do Paraná (1984) e Doutorado em Arquitetura e Urbanismo pela Universidade de Sáo Paulo (2000). Desde 2009 representa a UTFPR no programa de mestrado e doutorado Erasmus Mundus TPTI. Fez pós-doutorado na Faculdade de Educação da Universidade Federal de Minas Gerais (2011-2012) em educação ambiental e patrimonial; pós-doutorado em política científica e tecnológica no Instituto de Geociências da Unicamp-SP (2012), e estágio pós-doutoral no Colegio de la Frontera Norte, sede Monterrey, México sobre gestáo da água (primeiro semestre de 2018). 


\title{
TERRITORIAL DYNAMICS OF HOUSEHOLD ELECTRICAL AND ELECTRONIC WASTE IN MATINHOS-PR, BRASIL CITY
}

\begin{abstract}
This article deals with the territorial dynamics of household electrical and electronic waste in the city of Matinhos-PR. It is a city located on the coast of Paraná, which has areas of environmental preservation in the Atlantic Forest. It has a waste collect system directed by the Integrated Solid Waste Management Plan and has two associations of waste pickers and a non-governmental organization to collect, separate and commercialize reusable and recyclable materials. The objective of this article is to analyze aspects of the territorial dynamics of the collection and disposal of electronic waste that happen in a multifaceted social space in which the actors work with consent, with inequality, and with domination. It is a qualitative research, with the use of methodologies of interviews, observations and technical visits. The participation of public authorities in organizing the collect and destination of electronic waste has been relevant in the sense of creating policies, laws and decrees. However, there is a lack of synchrony among the actors, which participate in the process since industry to collectors and consumers. The final considerations showed that not everyone could build the process of collect and disposal of solid waste, because there are hierarchies regarding access to resources and information that causes undesirable dependency situations.
\end{abstract}

Keywords: territory, household electrical and electronic waste; associations of recyclable materials; Association Fukuoka Institute.

\section{INTRODUÇÁO}

A Organização das Naçóes Unidas (ONU) através da publicação do primeiro mapa global sobre lixo eletrônico (E-waste World Map), publicado no ano de 2013, apresenta em seu documento números alarmantes: Em 2012 a geração de lixo eletrônico fora aproximadamente 49 milhóes de toneladas. Isto representa a geraçáo de sete quilos de resíduos eletrônicos por habitante por ano no mundo. Conforme o estudo, os Estados Unidos lideram o ranking dos países que mais gera resíduos eletrônicos: 29,8 quilos de lixo por ano (LUNDERS; GALLUP, 2015, s/p).

Outras informaçóes divulgadas recentemente em Davos, na Suíça em 2019, no relatório da Plataforma para Aceleração da Economia Circular (Pace) e na Coalizão das Naçôes Unidas sobre lixo eletrônico, indicam que mais de 44 milhóes de toneladas de lixo eletrônico foram produzidas globalmente no ano de 2017. Conforme documentos, este montante equivale a mais de seis quilos de resíduos gerados para cada habitante/ano do Planeta.

Com base nestes dados, o estudo revela que o valor anual de lixo eletrônico global é superior a 62,5 bilhóes de dólares, mais que o Produto Interno Bruto (PIB) de muitos países. Se este ritmo persistir, estimativas apontam que em 2050 a produção de lixo eletrônico global deverá alcançar 120 milhóes de toneladas ao ano.

Conforme o E-waste World Map na América Latina, o Brasil aparece em posição de destaque no que se refere ao lixo eletrônico, ocupando o segundo lugar no ranking. Em 2012 o país produziu 1,4 milhão de toneladas de resíduos eletrônicos, o que equivale à média global de sete quilos por habitante/ano (LUNDERS; GALLUP, 2015, s/p).

A produção de bens e serviços, com técnicas e tecnologias modernas, articula-se com os demais setores da economia e tem diferentes graus de interação entre os atores. Nesta esteira, Santos (2004) explica que as atividades se pulverizam, especialmente as do comércio. 
A densidade e a distribuição das lojas no território, suas dimensôes, o crédito e a rotação das mercadorias corroboram com o imenso desenvolvimento da produçáo material. Este se alia ao aumento do consumo de energia, água, transporte, telecomunicação e uma divisão do trabalho com acentuada especialização. A pouca durabilidade e o volume dos materiais inorgânicos consumidos, com as transformaçôes tecnológicas, fez com que eles se tornassem lixo, uma mercadoria que passou a fazer parte do circuito produtivo. $\mathrm{O}$ recolhimento, o transporte, o tratamento e a disposiçáo destes restos da produção e do consumo tornou-se para cidade um gasto, e para as empresas contratadas um lucro (RODRIGUES, 1998).

As dinâmicas territoriais de apropriaçáo da natureza, do descarte e do destino dos Resíduos Sólidos Urbanos (RSU) acompanham mudanças socioespaciais no comportamento da sociedade do consumo, atitudes, valores e a internacionalização da base produtiva. A subordinação das políticas públicas às questôes ambientais provém das decisões tomadas na Conferência da Organização das Naçóes Unidas sobre Meio Ambiente e Desenvolvimento. A Agenda 21, um instrumento de planejamento, em um dos artigos do capítulo 4 do documento reza que a sociedade necessita encontrar soluçóes para reduzir a produção de resíduos. "Os Governos, juntamente com a indústria, as famílias e o público em geral, devem envidar um esforço conjunto para reduzir a geraçáo de resíduos e de produtos descartados" (BRASIL, 1992, p. 4). Sugere-se a reciclagem, redução dos desperdícios, a produção e o consumo de bens ambientalmente saudáveis.

No Brasil, para regulamentar o processo de coleta e disposição final, dentre outras decisóes, tem-se a Lei Federal n. 12.305 de 2010, que institui a Política Nacional de Sólidos (PNRS). Esta norma dispóe sobre definiçôes, diretrizes, princípios, objetivos, planos nacionais, estaduais e locais, responsabilidades dos geradores e do poder público, e instrumentos econômicos na gestáo dos RSU. Das dinâmicas no território para as ações realizadas por gestores municipais, sujeitos da coleta, cadeia de reciclagem, manejo e destino final dos RSU procedem ajustes e reformas contínuas de controle dos riscos potenciais ao ambiente.

Atuando nos territórios como fonte norteadora destas dinâmicas, a PNRS é o instrumento legal pelo qual a Uniáo, Estados e Municípios da Federação se orientam para resolução de um dos maiores desafios da sociedade de consumo: o consumismo e o descarte inadequado de resíduos, sobretudo de artefatos e equipamentos eletroeletrônicos.

Assim, a satisfação de necessidades básicas do cotidiano está justaposta com a separação de recicláveis, a compostagem, o reaproveitamento, reutilização e recuperação dos materiais. Percebe-se a importância de moldar nossos hábitos e comportamentos no sentido de tomar decisóes cidadãs na hora de adquirir produtos ou descartar resíduos. Essa decisão é preponderante e categórica para deliberar questóes ambientalmente sustentáveis na contemporaneidade.

Na pesquisa de Rodrigues (1998) sobre os programas de coleta seletiva da Prefeitura Municipal de Sáo Paulo iniciados em 1989, a autora verificou que a publicidade foi o motor das ações de separação do lixo domiciliar pelos moradores. Havia uma distribuição de sacos de lixo de papel para coletar os reciclados, além de explicaçóes para os moradores. As gestóes posteriores abandonaram a "doação" dos sacos de papel, alegando os altos custos do Projeto de Reciclagem, e colocaram contêineres em lugares estratégicos para que as 
pessoas colocassem neles o material reciclável. Não houve divulgação para os moradores das mudanças.

\begin{abstract}
Tentando verificar se realmente os contêineres se autodivulgam, realizamos algumas entrevistas com frequentadores de parques públicos onde há contêineres instalados. No Parque da Previdência por exemplo, foi entrevistado um grupo de vinte mulheres que frequentam aulas de ginástica quatro vezes por semana. A maioria náo traz o lixo para os contêineres. Pensavam que os contêineres destinavam-se apenas ao lixo gerado no próprio parque. Outras afirmaram que nunca tinham reparado nos contêineres (RODRIGUES, 1998, p. 175).
\end{abstract}

Em Raffestin (1993) a territorialidade pode ser caracterizada como uma dinâmica entre a sociedade e o espaço, sensível às variações temporais, mudanças nas gestóes, relaçóes de poder, interesses pessoais e políticos. Tal realidade abrange a problemática social e espacial da produção, circulação, distribuição e consumo. Santos (2005), ao estudar as tendências e perspectivas que se constituíram no território na construção e reconstrução do espaço com o auxílio da técnica e da ciência, contabiliza um aumento exponencial no número de artefatos. "Nos últimos 30 anos criaram-se sobre a face da Terra mais objetos do que nos 30 mil anteriores" (SANTOS, 2005, p. 122).

Eles estão em todos os lugares, e são criados com o auxílio da biotecnologia, cibernética, informática, eletrônica, e processos químicos. Por meio de artefatos físicos informatizados, o território se informatiza. Todos os objetos, segundo Milton Santos (2005), nascem com vocação mercantil, e dependem de corrente elétrica ou de campos magnéticos para funcionar. Dentre eles, citam-se os eletrodomésticos, eletroeletrônicos, monitores, equipamentos de informática e telecomunicação, fios, cabos, pilhas, baterias, lâmpadas, televisores, motores e tantos outros. Além de sua composição química, tecnológica e tipologias, os artefatos são especializados, com funçóes singulares, e contêm misturas de plásticos, vidros, alumínio, papel, dentre outros.

Toda esta complexidade dos materiais dificulta a reciclagem, uma das prioridades da PNRS. Nem todos os tipos de papéis, plásticos, metais e vidros são recicláveis. Comumente, não se conhece o processo de separação de materiais necessária para que estes sejam comercializados com as indústrias recicladoras. Por isso, o descarte correto é apenas uma primeira etapa da transformação dos materiais. "Mas esta "mercadoria" é simbolicamente considerada nos meios de comunicação apenas como atividade "economizadora" de recursos naturais, visando o bem comum. É esta a ponta do iceberg que é preciso deixar evidente para realizar análises mais complexas" (RODRIGUES, 1998, p. 208).

Outra característica dos objetos adquirida com a ciência e a tecnologia é a obsolescência programada, que reduz o ciclo de vida dos produtos. Neste sentido, o trabalho intelectual demandado para reduzir custos na fabricação de objetos transforma a resistência, a durabilidade dos materiais e estimula a produção de novos. Com o consumo ampliado e a gama de artigos ofertados nos diferentes setores, educação, lazer, serviços, saúde, viagens, informação, mais o crédito, a fatalidade do descarte destes produtos é certa.

Néstor García Canclini ao analisar a cultura do efêmero, explica que a arte, a política, e a moda são regidas pelas inovaçóes e obsolescência periódica. A surpresa e o 
divertimento precisam ser renovados, e são produtos sedutores. "Com efeito costuma-se imaginar o consumo como lugar do suntuoso e do supérfluo, no qual os impulsos primários dos indivíduos poderiam alinhar-se com estudos de mercado e táticas publicitárias" (CANCLINI2015, p. 35). Porém, o comportamento do consumidor não pode ser definido como irracional, uma vez que ele luta para obter o que a sociedade produz e pela maneira de usar os objetos.

A expansão do consumo se dá por processos socioculturais, com a participação da estrutura produtiva, publicidade, status, distinção, educação, desigualdade, moda, e das inovações. "A lógica que rege a apropriação de bens como objetos de distinção não é a da satisfação das necessidades, mas sim a da escassez desses bens e da impossibilidade de que outros os possuam" (CANCLINI, 2015, p. 63).

O significado sociocultural dos computadores e dos produtos elétricos e eletrônicos de última geração, por exemplo, pode estabelecer nuances de distinção e discriminação. Quando são postos à venda, são cobiçados, depois de adquiridos, são usados, explorados em suas potencialidades, comparados a outros e por fim tomam outros rumos. Na medida em que os objetos se especializam, as relaçóes entre sujeito e objeto se modificam. A aceitação mais pronta dos novos modelos, que permite chegar mais rápido aos objetivos estabelecidos e saltar etapas, podem causar distorçóes socioambientais provindas do descarte e da produção de resíduos.

Se os resíduos eletroeletrônicos domiciliares fossem descartados de forma inadequada, em ribanceiras de rios e lagos, quebrados ou não, eles promoveriam a poluição do ar, do solo, das águas superficiais e lençóis freáticos, tornando ainda, ambiente favorável para a proliferação de doenças. Pedro Jacobi (2004) menciona que estes materiais, ainda que sejam destinados aos aterros sanitários, eles não deixarão de poluir. Nestes espaços deveria haver um tratamento adequado dos líquidos produzidos na disposição (chorume), e isto não é feito na maioria dos municípios. "No caso da Região Metropolitana de São Paulo (RMSP) é um problema real já que uma parte significativa do lixo coletado nas 38 cidades são destinadas (sic) aos lixões" (JACOBI, 2004, p. 174-175).

A exposição ao chumbo, componente químico encontrado em soldagem de placas eletrônicas é cancerígeno e pode ocasionar danos ao sistema nervoso e sanguíneo. O Cádmio, presente em resistências e transistores, pode ocasionar risco de envenenamento, danos aos ossos, rins, próstata e anemia e câncer no pulmão. Além destes, metais pesados como o mercúrio presente nos televisores de tubo, monitores, pilhas, baterias e lâmpadas deterioram o sistema nervoso, causam perturbaçôes motoras e sensitivas, tremores e demência (CERRI, 2020).

A não geração, o recondicionamento, o reuso, a remanufatura e a reciclagem, apresentam-se como alternativas para minimizar estes impactos. Essa organização no território faz parte da existência coletiva, isto é, "hoje, a natureza é histórica...inclusive o chamado "meio ambiente". Seu valor "local" é relativo, ou, em todo caso relativizado" (SANTOS, 2005, p. 138). A ciência, tecnologia e informação precisam ser aliadas da gestão dos resíduos eletroeletrônicos, pois elas fazem parte do funcionamento do território e podem criar solidariedades com a PNRS. No seu Artigo 33, Parágrafo II, V e VII a Política determina que: 
[...] são obrigados a estruturar e implementar sistemas de logística reversa, mediante retorno dos produtos após o uso pelo consumidor, de forma independente do serviço público de limpeza urbana e de manejo dos resíduos sólidos, os fabricantes, importadores, distribuidores e comerciantes de:[...] Parágrafo II - pilhas e baterias; V - lâmpadas fluorescentes, de vapor de sódio e mercúrio e de luz mista; VI - produtos eletroeletrônicos e seus componentes (BRASIL, 2010).

De acordo com a demanda de equipamentos e serviços tecnológicos, frequência e uso dos objetos que mitigam a pressão sobre o tempo e o espaço, é possível incluir na escala de consumo mecanismos de redistribuiçáo e de troca para com o descarte destes produtos.

\begin{abstract}
A logística reversa é o instrumento de desenvolvimento econômico e social caracterizado por um conjunto de açóes, procedimentos e meios destinados a viabilizar a coleta e a restituição dos resíduos sólidos ao setor empresarial, para reaproveitamento em seu ciclo ou em outros ciclos produtivos, ou outra destinação final ambientalmente adequada (BRASIL, 2010).
\end{abstract}

O decreto n. 10.240 de 12 de fevereiro de 2020, regulamenta o artigo 56 da PNRS, e complementa o Decreto 9,177, de 23 de outubro de 2017, no qual importadores, distribuidores, fabricantes e comerciantes devem estruturar e implementar sistemas de logística reversa para os resíduos eletroeletrônicos domiciliares. O decreto do ano de 2020 define para quem o consumidor deve entregar o seu resíduo eletroeletrônico. No parágrafo V, do artigo 3, consumidores e usuários domésticos dos produtos eletroeletrônicos "entregam os referidos produtos em um dos pontos de recebimento estabelecidos, para fins de logística reversa e destinaçẫo final ambientalmente adequada" (BRASIL, 2020a).

Caso o consumidor não encontre este ponto de consolidação, concentração ou transbordo, o produto está órfāo porque o fabricante ou importador não está mais no mercado. Neste caso, no artigo 48, parágrafo IX, $\mathbb{\$} 4$ o "os responsáveis pelo sistema de logística reversa darão destinação final ambientalmente adequada a cem por cento dos produtos eletroeletrônicos recebidos, inclusive aos produtos órfãos e cinzas".

As práticas de gerenciamento da administração municipal para com os resíduos eletroeletrônicos domiciliares são insipientes. No Plano de Gerenciamento Integrado Resíduos Sólidos de fevereiro de 2012, coordenado pelo Secretário Municipal de Meio Ambiente, na estrutura operacional dos serviços de limpeza pública, os resíduos eletroeletrônicos domiciliares não constam nas categorias de resíduos gerados no município. Considera-se neste Plano somente os resíduos sólidos urbanos, aqueles provenientes dos domicílios (orgânicos, recicláveis e rejeitos) e da limpeza pública (varrição, limpeza de logradouros e outros) (PREFEITURA MUNICIPAL DE MATINHOS, 2012).

Observa-se nas ruas das cidades o despejo deste lixo e a omissáo dos moradores que compartilham do desleixo e da sujeira. "A questão do despejo dos resíduos sólidos tem se tornado altamente problemática na maioria das cidades" (JACOBI, 2004, p. 172). Quando não se pode criar formas novas, é preciso fazer adaptaçóes. Então, a organização da coleta seletiva e a logística reversa são responsabilidades compartilhadas, e conforme a PNRS, os produtos e embalagens considerados ou não resíduos perigosos devem retornar aos comerciantes e distribuidores (ver figura 1). 
Figura 1 - Logística Reversa definida na PNRS.

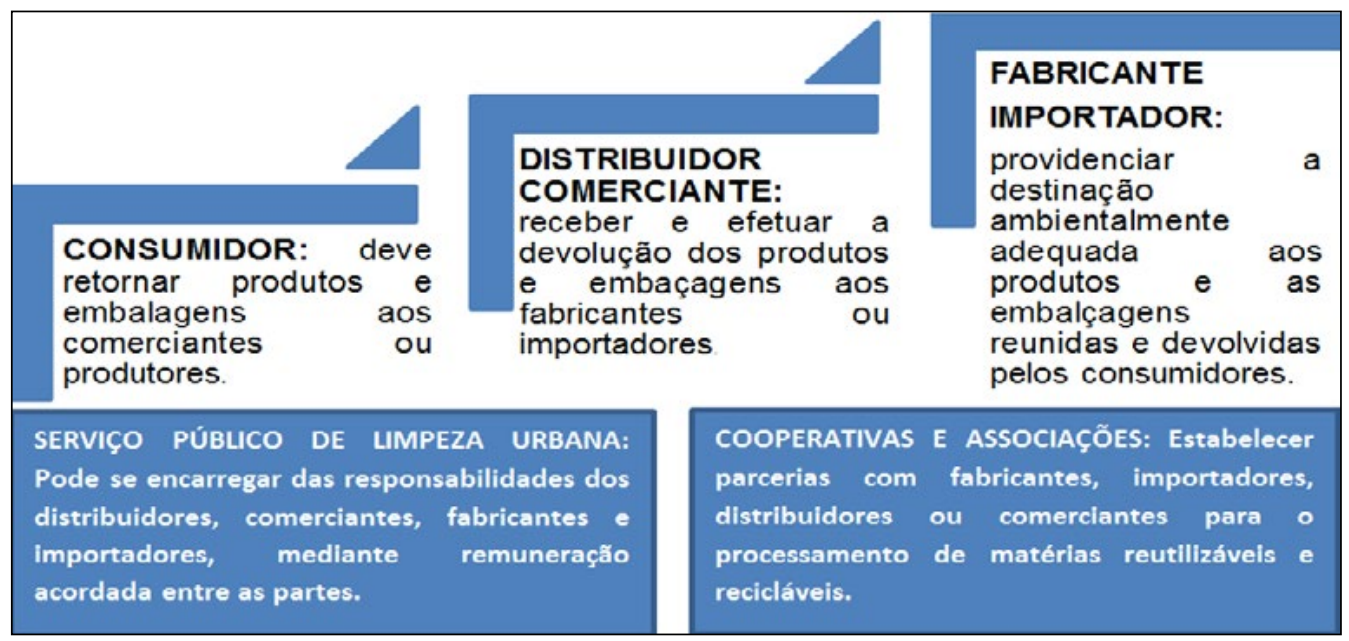

Fonte: Adaptado da PNRS (2010).

A organização, a manutenção e a disponibilização de informaçóes sobre a realização das respectivas atividades propostas no esquema na Figura 1 passa pela evolução interna das estruturas administrativas públicas e privadas. Nas dinâmicas territoriais para os RSU, a coleta de materiais recicláveis traz a noção de preservação para o bem comum, e oculta a destruição de bens naturais no espaço.

O desenvolvimento dos territórios é dinâmico, e precisa contemplar os aspectos socioculturais e as identidades socioambientais, compreendendo a açáo dos atores sociais, recursos e competências (HAESBAERT, 2004; SAQUET; SPOSITO, 2008; SANTOS, 2005). Neste estudo, à luz do território e das ideias apresentadas pelos autores selecionados, objetivou- analisar aspectos das dinâmicas territoriais da coleta e disposição de resíduos eletroeletrônicos que acontecem num espaço social multifacetado em que os atores trabalham com o consentimento, com a desigualdade, e com a dominação.

\section{METODOLOGIA}

Para abordar o tema da coleta e disposiçấo de resíduos eletroeletrônicos dos domicílios trabalhou-se com a metodologia qualitativa de análise e interpretação de dados. Foram feitas entrevistas semi-estruturadas com os administradores municipais que participam da coleta e disposição dos RSU e com os presidentes das duas Associaçóes de Catadores de Materiais Recicláveis e Instituto Fukuoka. No decorrer das visitas técnicas aos locais onde os atores desenvolvem suas atividades foram sendo estendidas visitas para outros espaços de depósitos de resíduos. Isto aconteceu em diferentes datas durante os anos de 2018 e 2019. Os pesquisadores obtiveram termos de consentimento para publicar informaçóes coletadas, e estes documentos estão disponíveis na tese de doutorado (DULLIUS, 2020).

Flick (2009) considera que existem relações dinâmicas entre situaçôes que acontecem nos lugares e as açôes dos sujeitos que podem ser observadas, registradas e analisadas. Trata- 
se de uma pesquisa ativa, uma vez que ela auxilia na vivificação de algum tipo de mudança desejada, implicando em uma tomada de consciência do investigador e do investigado, dos próprios problemas e fatos que determinam estabelecer objetivos e condições, elaborando um meio para superá-los (CHIZZOTTI, 2006).

\section{FUNCIONAMENTO DA COLETA DE RSU EM MATINHOS-PR}

A cidade de Matinhos-PR é um município da região litorânea do Paraná, localizado na Mata Atlântica, e está a 111 quilômetros da capital. Tem uma população flutuante (500.000), pois possui moradias de veraneio e moradores que ali vivem o ano todo (30.000 pessoas). Tem um pequeno centro histórico e 36 balneários com 17 quilômetros de praias. É uma área de reserva de carbono, de biodiversidade e de água. Tem extensas áreas de preservação ambiental, com dois parques que estão em diferentes municípios: Parque Nacional de SaintHilaire Lange e Parque Estadual Florestal do Rio das Onças (PREFEITURA MUNICIPAL DE MATINHOS, 2012).

A Câmara Municipal de Matinhos instituiu por meio da lei municipal n.1098, de 13 de abril 2007, a Política Municipal de Resíduos Sólidos. Ela classifica os tipos de resíduos, de coletas e de disposição, e inclui o fomento para a formação e participação de cooperativas e associaçóes de trabalhadores autônomos na coleta, triagem e beneficiamento dos materiais reutilizáveis ou recicláveis. Neste estudo, adota-se o conceito da norma, artigo 3, sobre resíduos: "materiais resultantes do processo de produção transformação, utilização ou consumo, oriundos de atividades humanas ou animais, ou decorrentes de fenômenos naturais, a cujo descarte se procede, se propóe proceder ou se está obrigado a proceder" (CÂMARA MUNICIPAL DE MATINHOS, 2007).

Os resíduos sólidos urbanos (RSU) abarcam aqueles nos estados sólido, líquido e gasoso, gerados em atividades humanas que necessitam a administração por meio de estratégias, instrumentos, políticas e decisões. O gerenciamento, por sua vez, é um "sistema de gestão dos processos internos ou externos de segregação, acondicionamento, identificação, coleta, manipulação, transporte, armazenamento, reaproveitamento, tratamento e destinação final dos resíduos sólidos” (CÂMARA MUNICIPAL DE MATINHOS, 2007).

Não possui um aterro sanitário, mas compartilha em forma de consórcio, com o município vizinho de Pontal do Paraná, a disposição dos resíduos (Consórcio Intermunicipal para Aterro Sanitário (CIAS). Ele está localizado na Mata Atlântica. Na Política Municipal, o aterro é compreendido como uma técnica específica de confinamento, a qual minimiza os impactos ambientais dos resíduos sólidos urbanos. Deve ser um local impermeabilizado com drenagem das águas, de modo a receber os resíduos, que devem ser cobertos por camadas com material inerte (CÂMARA MUNICIPAL DE MATINHOS, 2007).

O sistema de coleta para os orgânicos e recicláveis está sob a responsabilidade da administração municipal e de duas associações de catadores e selecionadores de materiais recicláveis. Não há os serviços de varrição, capina, catação manual em todas as ruas e praias. $\mathrm{Na}$ cidade estão distribuídas grandes caçambas etiquetadas com as cores verde e marrom, onde os moradores podem depositar os resíduos (DULLIUS, 2020). 
Para a separação dos resíduos recicláveis ou reutilizáveis foram construídos, pela Prefeitura, dois Barracóes, sendo um ocupado por uma associação de trabalhadores autônomos e o outro foi destinado para o depósito de resíduos eletrônicos. As dinâmicas territoriais dos resíduos eletroeletrônicos domiciliares em Matinhos-PR ocorrem majoritariamente por meio da organizaçáo de coleta de sucatas eletrônicas realizada não pelas associaçóes de catadores. Não consta na Política Municipal uma definição para este tipo de resíduo. Não há também o conceito de eletroeletrônico, que inclui na logística reversa exclusivamente equipamentos de uso doméstico, comercializados no mercado interno, como embalagens, computadores e seus componentes, aparelhos, cabos, telefones e outros.

A logística reversa da PNRS para os resíduos eletroeletrônicos impóe aos geradores a responsabilidade (custeio do processo e organização) para que os materiais eletrônicos retornem para os fabricantes. $\mathrm{O}$ decreto 10.240 regulamenta esta ação para os produtos domésticos. "Art. 47. A implantação do sistema de logística reversa tem como objetivo a criação e a estruturação de um sistema para recebimento e destinação final ambientalmente adequada de produtos eletroeletrônicos de uso doméstico, constantes no Anexo I." (BRASIL, 2020a).

No município de Matinhos tal encaminhamento é viabilizado pela gestão municipal. A Associação Fukuoka Instituto ${ }^{3}$ é subvencionada pelo município para realizar esta atividade. Esta coleta os resíduos eletroeletrônicos domiciliares. A Associação tem uma parceria com o Município de Matinhos-PR desde janeiro de 2014. A parceria envolve também a coleta dos resíduos tóxicos. A Associaçáo pode coletar 18 tipos de resíduos, dentre os quais: lâmpadas de todos os tipos; pilhas e baterias diversas; baterias de celulares e notebooks; baterias veiculares e estacionárias; reatores de luminárias; medicamentos vencidos; bitucas de cigarro; óleo de fritura; eletroeletrônicos e informática; latas de tintas e solventes; chapas de raio-X; isopor; banners e faixas de lona; vidros; pneus; filtros de óleo e ar; Equipamentos de Proteçâoo Individual (EPI's); óleos lubrificantes incluindo materiais recicláveis. "Estes materiais, são considerados os piores em termos urbanos. São perigosos, tóxicos e especiais" (DEPOIMENTO 1, 2019).

A associação Fukuoka foi qualificada em 20 de março de 2017 pela Organização da Sociedade Civil de Interesse Público pelo Ministério da Justiça e Cidadania (OSCIP). Em primeiro de novembro de 2018, foi caracterizada como ponto de consolidação para logística reversa de pilhas no Estado do Paraná, pela gestora para resíduos de equipamentos eletroeletroeletrônicos nacional, a Green Eletron. Em 2013, foi declarada associação de utilidade Pública Estadual pela Lei n. 17.703, e de Utilidade Pública Municipal (Curitiba), e pela Lei n. 14.147, de 20 de novembro de $/ 2012^{a}$. Além disso, há de se registrar que no Brasil ela é a única Organização Não Governamental (ONG) que coleta e destina para

3 ASSOCIAÇÃO FUKUOKA INSTITUTO é dirigida por Edson Sadao Imoto - Diretor de Meio Ambiente. A unidade operacional: está localizada na Rua Tenente Sandro Luiz Kampa, 170 - bairro Parque da Fonte - CEP 83050-695 - São José dos Pinhais - Paraná. Possui escritório: na rua Alameda Dr. Muricy, 474 - $4^{\circ}$ andar - conj. 42a - Centro - CEP 80010-120 - Curitiba - Paraná. E-mail: eimoto@bol.com.br Celular / WhatsApp: (41) 999-76-3321 
reciclagem lâmpadas fluorescentes tubulares e compactas. Ou seja, existe um aporte técnico consolidado que está disponível para o município de Matinhos -PR.

\section{RESULTADOS E DISCUSSÓES}

Conforme o diretor do setor de meio ambiente da Associaçáo Fukuoka Instituto, os resíduos são depositados no barracão localizado na cidade, cedido pela Prefeitura, e mensalmente, eles são recolhidos pela Logística de coleta da Unidade Operacional da Fukuoka localizada no município de São José dos Pinhais. Esta cidade faz divisa com os municípios litorâneos e com a capital do Estado.

$\mathrm{Na}$ sequência da logística, a Associação entra em contato com empresas compradoras dos materiais, e com as quais mantém parcerias, para realizar as transaçóes comerciais. Existem duas empresas que fazem a reciclagem destes materiais no sul do país: Reciclatech (Colombo) e Ecotrade (Fazenda Rio Grande), ambas as fábricas localizadas na Regiấo Metropolitana de Curitiba. Essas empresas dão destino ambientalmente correto aos materiais, certificando as associações que fazem a coleta destes resíduos.

A Prefeitura Municipal de Matinhos disponibiliza também o agendamento da coleta pelo número de telefone 156. Este é o canal de comunicação com a administração municipal disponível para os cidadáos interessados em descartar este tipo de resíduo. De posse de informações de localização, tipo e quantidade de material, a Prefeitura repassa as informações ao funcionário da Associação Fukuoka para que ele vá até o local e recolher o material.

Em Matinhos, o material deveria ser armazenado e separado em uma estação de transferência (transbordo), ou seja, no barracão acima mencionado. Na figura 2, vê-se o imóvel que está localizado no bairro rio da Onça.

Figura 2 - Estação de Transbordo de Resíduos eletroeletrônicos domiciliares de Matinhos-PR

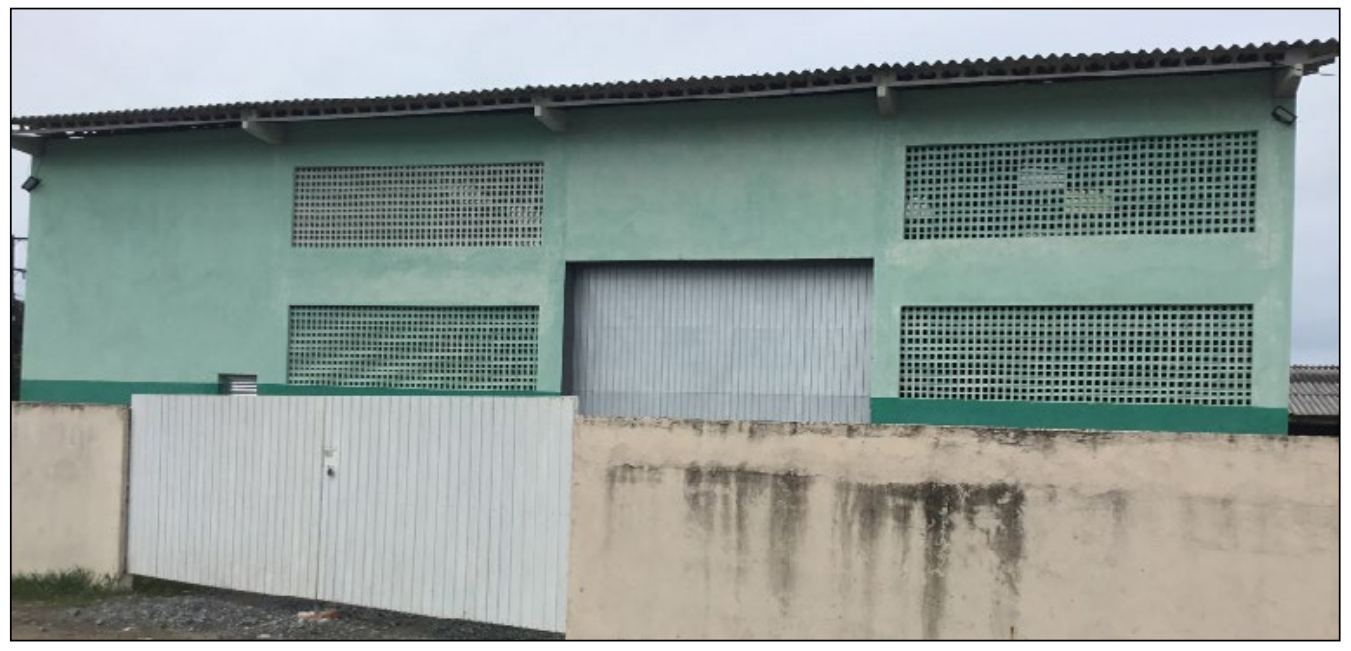

Fonte: Dos autores (2019). 
Neste convênio com a associação Fukuoka, a Prefeitura Municipal de Matinhos decidiu ceder o barracão destinado à segunda Associação de Catadores, que não quis assumir o espaço porque os equipamentos de separação não estavam completos, para o armazenamento dos resíduos eletroeletrônicos domiciliares.

Quando o morador entrega o material corretamente para a Associaçáo Fukuoka, a Prefeitura fornece um recibo. Posteriormente, ocorre a certificação pelas empresas recicladoras. A Associaçáo Fukuoka, ao realizar este trabalho, agrega valor aos resíduos eletroeletrônicos e coopera para que não ocorra o descarte incorreto. Alguns materiais são exportados. A cidade faz parte de um nicho internacional de logística reversa. Segundo informaçóes dos gestores, estima-se que em cinco anos, tenha sido destinado corretamente mais de 1.000 toneladas de resíduos eletroeletrônicos.

Este projeto é uma iniciativa da municipalidade sob a responsabilidade da SEMAM. Ele é pioneiro no litoral, uma vez que os demais (seis municípios) não possuem uma organização como esta para a logística reversa de resíduos eletroeletrônicos domiciliares.

O relato de um dos gestores destaca algumas fragilidades da proposta. Segundo ele, a proposta possui vulnerabilidades quanto ao convênio, "não tem educação ambiental, não tem mídia, não tem Pontos de Entrega Voluntários (PEVs), sendo um dos motivos que o tornam falho. A Fukuoka mantém um funcionário com uma Kombi e um telefone" (DEPOIMENTO 2, 2019). Não há legislaçôes, projetos e programas conjuntos entre as secretarias de Meio Ambiente, Infraestrutura e Educação para organizar a coleta de resíduos eletroeletrônicos.

\section{ESPAÇO FÍSICO: O CONFLITO DO BARRACÁO}

Antes da Associação Fukuoka receber este barracão, ela depositava os resíduos em um imóvel na entrada da cidade em mau estado de conservaçáo e sem ligação com os serviços de água e luz. Existe um Termo de Ajustamento de Conduta (TAC) entre Ministério Público do Trabalho e o Município de Matinhos que determina que o uso deste espaço pertence à Associação dos Coletores e Selecionadores de Resíduos Sólidos de Matinhos (ANCRESMAT). Ela é uma das associaçóes responsável pela coleta de materiais recicláveis na cidade. Entretanto, existe um impasse entre a ANCRESMAT e a Prefeitura de Matinhos para entrega do local.

A associação ANCRESMAT diz que o espaço operacionalmente não serve para eles. Há irregularidades e por este motivo ficou abandonado quase um ano. Uma comunicação extraoficial foi dada à ANCRESMAT para manifestarem-se pelo interesse no espaço em um prazo de 30 dias. Como isso náo ocorreu, a Prefeitura decidiu ocupar este espaço para armazenar os resíduos eletroeletrônicos domiciliares.

Todavia, há que se relatar que os gestores municipais, encontram-se respondendo processo por improbidade administrativa devidos às falhas estruturais no barracão. Dentre estas, pode-se citar espaços nos beirais das telhas, que acabam dando acesso a pombos que entram no barracão, depositando fezes sobre os materiais que lá se encontram.

Além disso, o local impede o fluxo de movimentação dos caminhóes para transbordo de materiais recicláveis. Isto porque o projeto previu apenas a entrada do caminhão e não 
a saída dele, inviabilizando o uso de uma esteira de triagem que deveria ficar na entrada do barracáo, equipamento este que foi adquirido especialmente para o processo de separação de materiais.

Alguns esforços de planejamento de ocupação de outros espaços do terreno foram feitos pela Universidade Federal do Paraná (UFPR), Setor litoral. Na ocasião da visita, em 2019,(que foi realizada quando?), a área desocupada do lote mostrou a viabilidade de realização de trabalhos comunitários, como por exemplo, uma horta orgânica e atividades de compostagem. Professores e estudantes dos cursos de graduaçáo teriam condiçóes de auxiliar nestas ações com os moradores do entorno. O poder público inviabilizou o uso do espaço para Universidade, reforçando conflitos já existentes entre as partes.

No espaço há três banheiros, sendo um deles para pessoas com deficiência, um local para instalar um escritório e existe ligaçóes para os serviços de água e luz. Os custos de manutenção ficam ao cargo da municipalidade. Em visita ao local, os pesquisadores verificaram que ali não está sendo depositado somente resíduos eletroeletrônicos domésticos. Foram registrados resíduos de construção civil, placas de isopor contaminadas com cimento (aproximadamente 25 metros cúbicos), pneus, madeiras, geladeiras, televisores, rádios, batedeiras e bebedouros (ver figuras 3 e 4).

Figura 3 - Disposiçấo inadequada dos resíduos no interior do barracáo ocupado pela Fukuoka em Matinhos-PR.

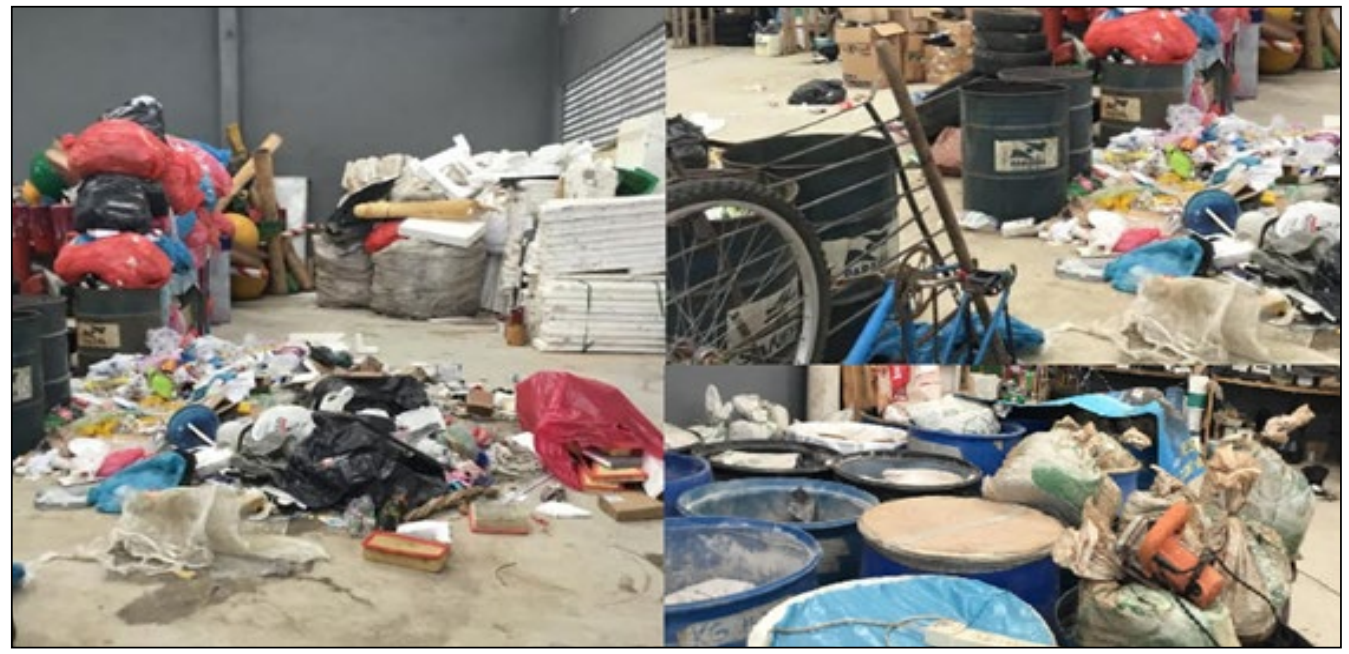

Fonte: Dos autores (2019).

E mais lâmpadas armazenadas e empilhadas de forma incorreta, pets dos mais diversos tipos como baldes e garrafas plásticas, tonéis contendo materiais sem identificação, outros com óleo e lubrificantes, pilhas e baterias expostas ao chão. Materiais de decoração utilizados para decorar a praça da cidade nas festividades natalina estavam no interior do galpão próximo há lâmpadas quebradas. Cabe ressaltar que neste local, que está armazenando estes tipos de materiais citados, há o risco de contaminaçáo pelo mercúrio e outros metais pesados. 
Figura 4 - Enfeites de Natal, galóes de plástico, móveis, resíduos eletroeletrônicos dispostos no Barracão da Fukuoka em Matinhos-PR

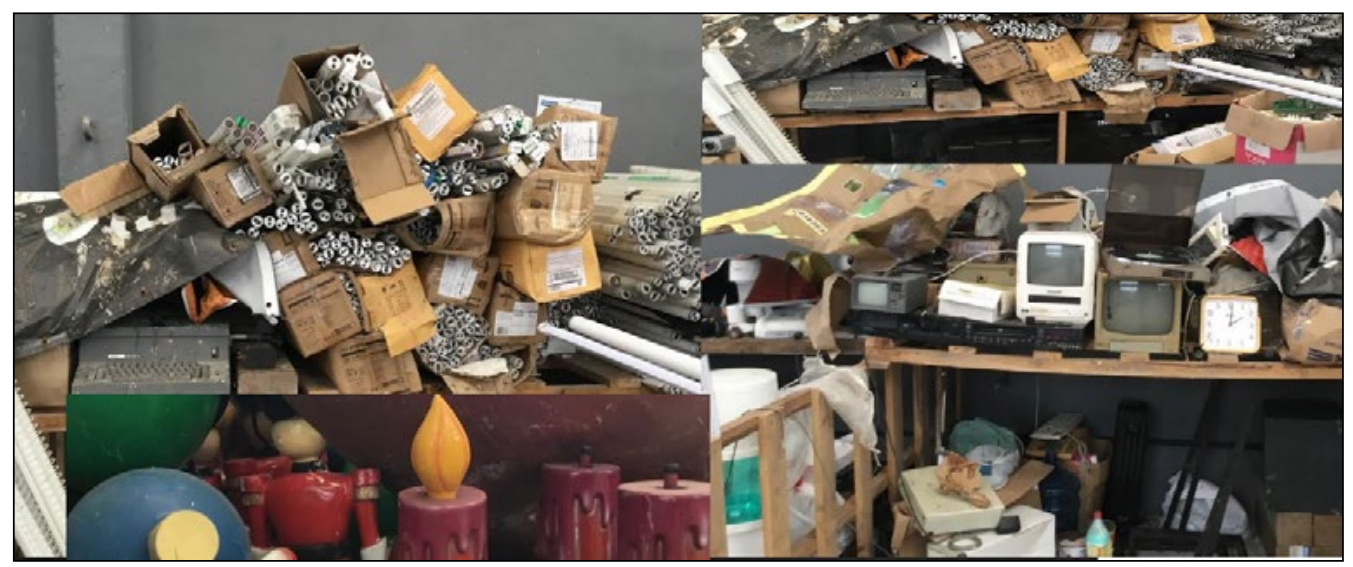

Fonte: Dos autores (2019).

Com os resíduos eletroeletrônicos pode-se criar um museu. Um funcionário da Prefeitura relatou este interesse em expor máquinas e peças que não são mais fabricadas e que podem auxiliar o visitante a entender por quais caminhos a sociedade começou a sua informatização. Mas, politicamente, precisaria ser negociado um espaço, o que é um item custoso no orçamento municipal. As gestóes dos prefeitos vão acontecendo e nada se cria. 'Eu não tenho domínio em alguns territórios dos resíduos. O meu perfil é mais fazer ações no meio ambiente, eu prefiro resolver com as minhas próprias mãos aquilo que eu posso fazer como funcionário na Prefeitura” (DEPOIMENTO 3, 2019).

Por outro lado, exposiçóes itinerantes começam a surgir como ação de educação ambiental para divulgar e coletar resíduos eletroeletrônicos. A figura 5 apresenta um recente roteiro que pode ser analisado como uma ação de educação ambiental in loco, criado pela Secretaria de Meio Ambiente de Matinhos (SEMAM). Estas ilustrações de textos significativos visam colaborar para mudanças de postura e instituição de agentes defensores de causas legítimas pelo descarte correto de resíduos gerados no território. 
Figura 5 - Roteiro de divulgação das coletas de resíduos eletroeletrônicos domiciliares.

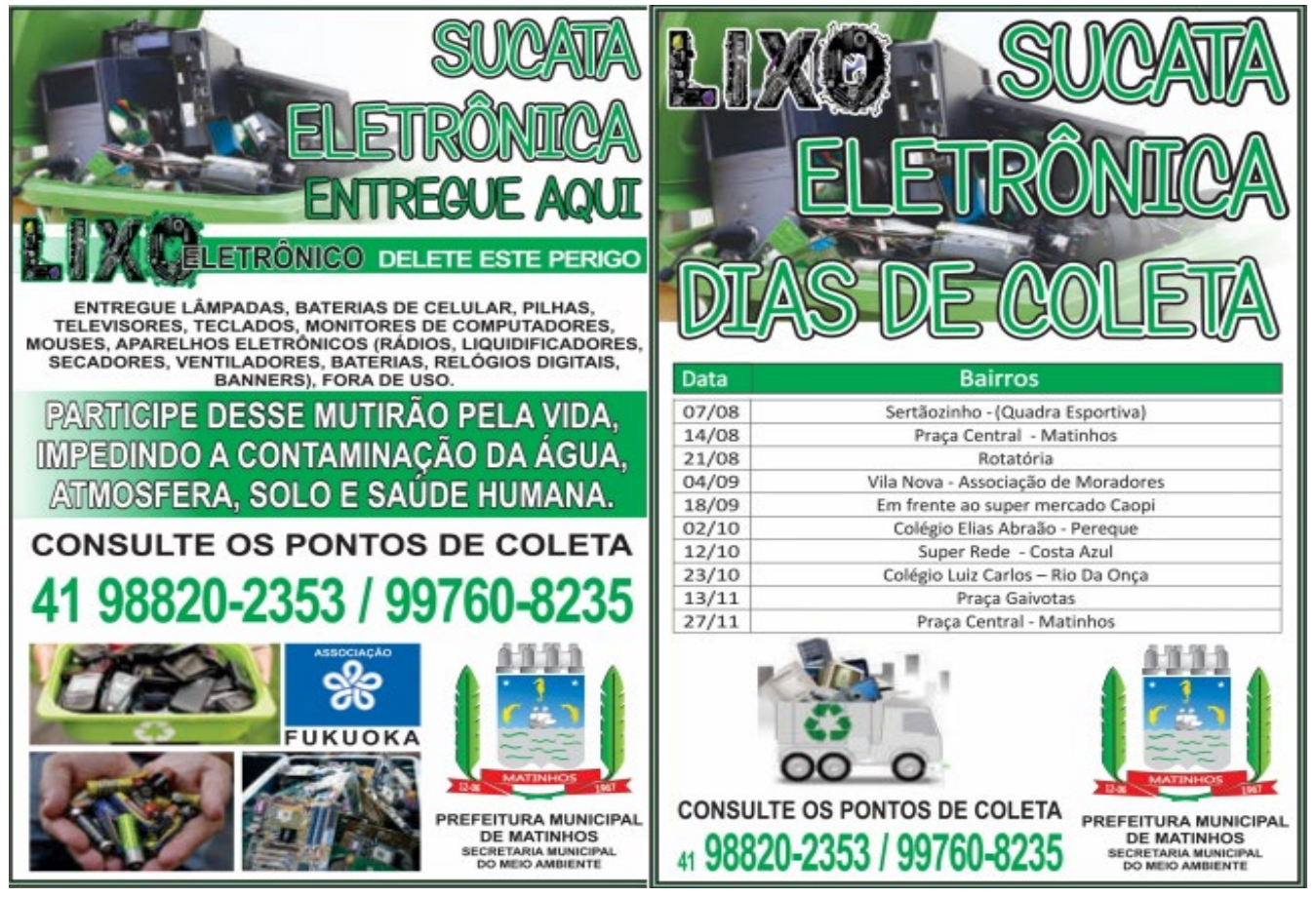

Fonte: Parque Nacional de Saint-Hilaire/Serra Da Prata, 2019.

O texto da campanha de mobilização dos moradores é convidativo, e inicia com uma justificação: a contaminação. Se a administração pretende fazer trocas com a população, esta seria a oferta qualidade de vida no litoral, sem poluição na água, no solo e no ar em troca do mau descarte dos possuidores de objetos indesejados. Parece haver pouca distância entre os diferentes atores e os espaços sociais que ocupam, uma vez que se trata de uma operaçáo conjunta, e os eventuais méritos poderiam ficar para ambos. Abaixo, no texto, observa-se que a argumentação procura dar sentido prático às lógicas de participação de atividades sociais.

[...] Participe desse mutirão pela vida, impedindo a contaminação da água, atmosfera, solo e saúde humana. Entregue lâmpadas, baterias de celulares, pilhas, televisores, teclados, monitores de computadores, mouses, aparelhos eletroeletrônicos, rádios, liquidificadores, secadores, ventiladores, baterias, relógios digitais, banners que estejam fora de uso. Consulte os pontos de coleta: 41 9.8820-2353 / 9.9760-8235. Prefeitura Municipal de Matinhos, Secretaria Municipal de Meio Ambiente e Associação Fukuoka PARQUE NACIONAL DE SAINT-HILAIRE/SERRA DA PRATA, 2019).

Muito embora, essa iniciativa possa parecer discreta, ela denota esforços no sentido de promover o melhoramento da coleta e a conscientização no descarte de resíduos eletroeletrônicos domiciliares. Trata-se de uma estratégia coordenada, dentre várias, 
econômicas, de investimento social, culturais, para garantir também a atividade econômica da reciclagem. Santos (2005) explica que "as próprias atividades implantadas ex-ofício pelo poder público, apesar de ser teoricamente um fruto do seu poder locacional discricionário, são na maior parte das vezes, atraídas ou sugeridas pelas atividades econômicas já existentes ou a implantar-se "espontaneamente"” (SANTOS, 2005, p. 82).

\section{VISITA TÉCNICA EM 2019 (quando?)}

Em visita técnica ao barracão dos resíduos eletroeletrônicos, os pesquisadores identificaram a não coleta convencional dos resíduos domiciliares do bairro, conforme mostra a figura 6. Uma caçamba de orgânicos, localizada no lado de fora, estava no seu limite, contendo materiais orgânicos e recicláveis, resíduos vegetais e de construção civil, dentre outros. $\mathrm{Na}$ área externa do barracão havia animais mortos e materiais espalhados no solo.

Figura 6 - Vista lateral e externa do barracão para depositar resíduos eletroeletrônicos de Matinhos-PR.

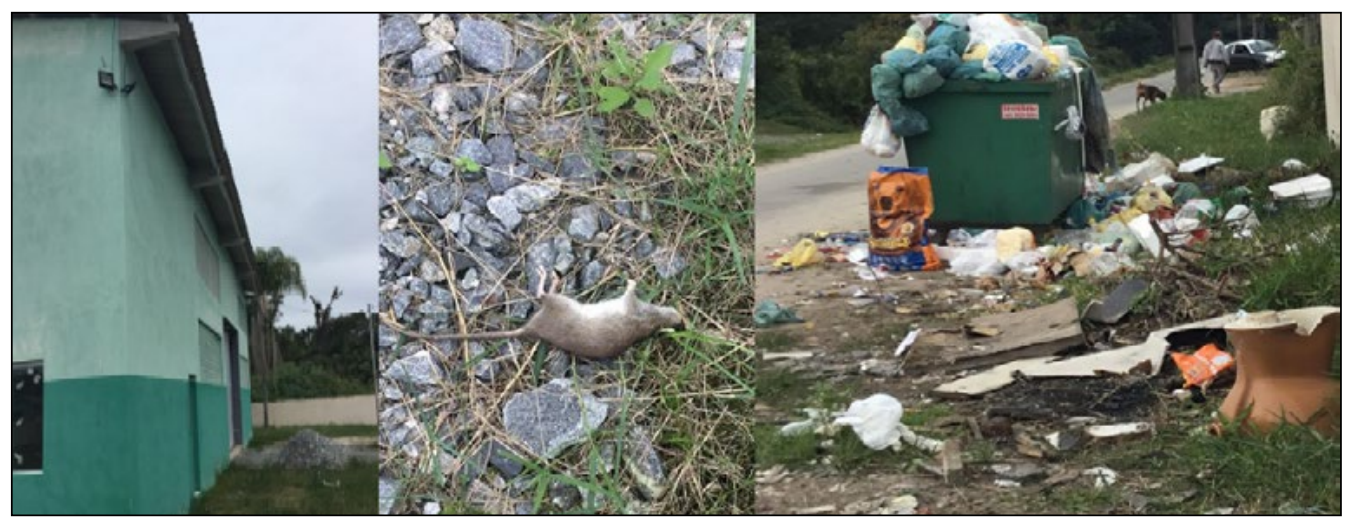

Fonte: Dos autores (2019).

Os materiais eletroeletrônicos descartados pela população em qualquer espaço físico são chamados de resíduo eletrônico órfão. A incorporação desta ideia gerou a construção de um espaço conhecido em Matinhos como "cemitério de eletrônicos". Ali, o problema dos resíduos eletroeletrônicos órfãos se diversifica dada a heterogeneidade da composição dos resíduos que passa a interagir com o Rio da Onça ${ }^{4}$. Para um entrevistado, faltam diálogos entre as associaçóes que coletam materiais recicláveis e eletroeletrônicos domiciliares e "nem com o caminhão do resíduo vegetal ou da coleta convencional, pois eles já poderiam

4 O Rio da Onça é conhecido na cidade de Matinhos. Ele está localizado nas proximidades da região central. Possui um parque com mesmo nome: Parque Estadual Rio das Onças. No passado, era um depósito de lixo do município de Matinhos e, hoje, abriga grande parte da flora e da fauna da mata atlântica. Esta Unidade de Conservação (UC) foi criada em 1981 e é gerenciada pelo Instituto Ambiental do Paraná (IAP). A UC localiza-se a 600 metros da praia. Seu acesso é realizado pela PR 412, no Balneário Riviera II. Disponível em $<$ http://www.iap.pr.gov.br/modules/noticias/article.php?storyid=653> . 
ter retirado todo este material que está aqui poluindo o solo e o nosso rio da Onça" (DEPOIMENTO 4, 2019).

Além da contaminação que está ocorrendo cotidianamente, com a liberação de produtos químicos no solo e na água, o volume de resíduos no local cresce. Com as chuvas, o lixo acumula água, favorecendo a proliferação de mosquitos (ver figura 7).

Figura 7 - Descarte inadequado de resíduos eletroeletrônicos no município de Matinhos-PR

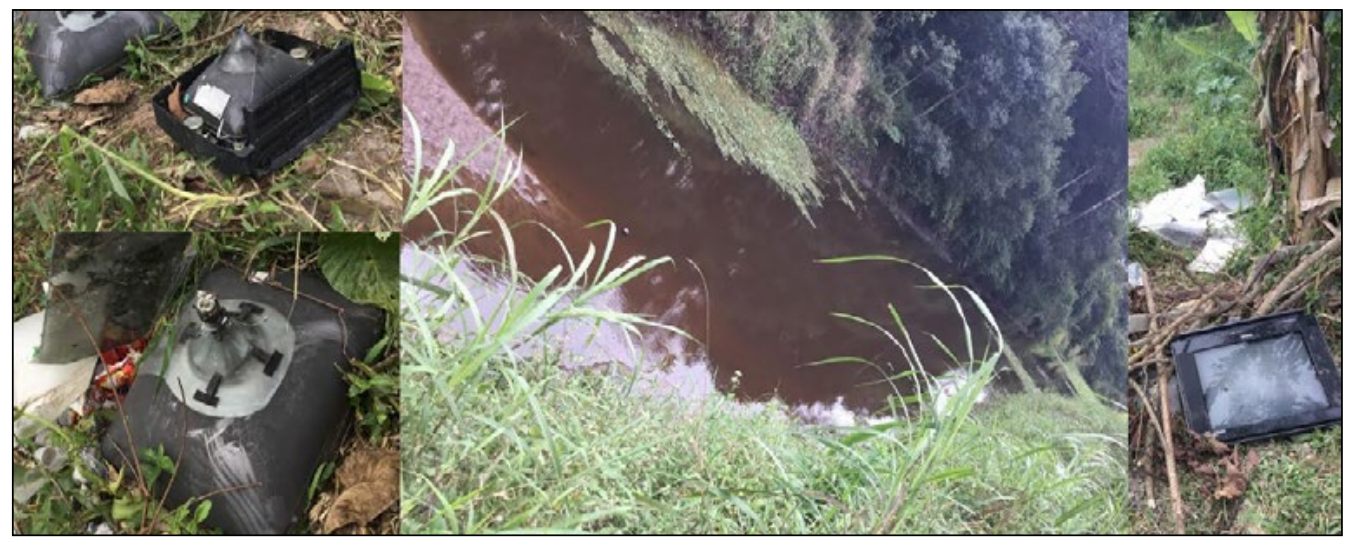

Fonte: Dos autores(2019).

$\mathrm{Na}$ trajetória entre as necessidades e as urgências existem propostas de formar equipes de trabalho, equipamentos e veículos para coletar os materiais dispostos indevidamente no território do município para evitar o agravamento dos problemas ambientais que já existem. "Precisamos fazer barulho na cidade. Orientar e informar a nossa população. Até me surpreendi, que a ideia da ação de educação ambiental itinerante tenha avançado. Porque há resistências, o autoritarismo é uma essência aqui” (DEPOIMENTO 5, 2019).

Do ponto de vista econômico, o território de Matinhos é considerado pouco operacional na gestão dos RSU recicláveis, se comparado com outros municípios brasileiros. Dullius, et al. (2018) salientam a forma pretensamente exclusivista da gestáo local e o domínio sobre as ações dos atores da coleta de materiais recicláveis da cidade. No estudo, confirmou-se o uso do princípio da exclusividade, o domínio e os interesses específicos da gestáo municipal contrários aos princípios da PNRS para a coleta seletiva, participaçáo dos catadores, e disposição dos resíduos no aterro sanitário, comprometendo a paisagem, o ambiente, o sistema de coleta seletiva, a comercializaçáo dos materiais e os ganhos dos catadores.

O local de depósito de RSU de Matinhos e de Pontal do Paraná, titulado Aterro Sanitário do Pontal do Paraná/PR ou aterro (CIAS), está no limite da sua capacidade operacional. Os resíduos eletroeletrônicos, recicláveis e orgânicos são simplesmente depositados no solo, sem qualquer tipo de tratamento, e não há uma lagoa de contenção adequada para conter o chorume. As células abertas funcionam como lixóes, provocando combustóes dos gases, poluição da atmosfera e das águas. Para ampliar a capacidade do 
“aterro", são necessários procedimentos e licenças ambientais que implicam em custos e burocracias (JACOBI, 2004; DULLIUS et al, 2017).

Além desta infraestrutura adensada, que poderia ser mitigada com os programas de separação, coleta e comercialização dos materiais recicláveis, encontram-se as dificuldades sociopolíticas de dar voz aos catadores organizados em associaçóes na coleta seletiva. Por ocasião de negociaçôes entre estes grupos sociais e as autoridades públicas, os pesquisadores presenciaram situaçóes de dominação política e relações institucionalizadas de controle e poder na organizaçáo da coleta de resíduos da cidade. Em especial, as hostilidades e os enfrentamentos acrescem durante a temporada de veraneio, quando a quantidade de resíduos produzidos é gigantesca e verbas do governo do Estado, da companhia de água e de energia entram nos cofres públicos (DULLIUS et al. 2018).

A gestão dos RSU pode ser comparada a uma batalha, uma peleja diária contra a geração e disposição de resíduos, nas indústrias, nos domicílios, nas propriedades rurais, pois muitos deles não têm destino adequado, senão lixôes e depósitos clandestinos. Como a indústria eletroeletrônica trabalha com inovaçóes tecnológicas, e seu mercado depende das novidades, caberia a ela apresentar projetos de reaproveitamento dos materiais que são empregados nas mercadorias. Da parte dos administradores públicos, cumpriria cuidar do descarte e do tratamento final dos rejeitos, criar áreas ambientalmente adequadas para dispor e tratar a heterogeneidade, a discrepância e a diversidade dos materiais coletados. Os consumidores, não importando sua posição socioeconômica, sobretudo aqueles que vão esporadicamente para o litoral paranaense, e demais cidades litorâneas, poderiam colaborar entregando os resíduos para quem sanciona e garante o bom desempenho e o êxito da coleta.

No Anexo I da Lei 10.240/20, a qual implementa o sistema de logística reversa de produtos eletroeletrônicos e seus componentes de uso doméstico, estão listados mais de 200 produtos que fazem parte deste sistema de descarte adequado. A norma diz que outros produtos podem ser acrescentados à lista. Fazendo uma projeçấo sobre o número de pessoas ocupadas em Matinhos (9.421 IBGE), sobre a vida útil dos objetos, imaginando que cada uma possa ter de cinco a dez destes itens listados, e que as pessoas descartem um por ano, seriam mais de nove mil objetos no solo por ano, seja onde eles forem depositados.

Isto significa que é necessário contar com a seriedade do núcleo conceitual deste Decreto de responsabilidade compartilhada, para que não ocorra exaustão das alternativas de disposição de resíduos eletroeletrônicos domiciliares e consequente contaminação das superfícies e das águas. A cidade de Matinhos-PR precisaria rever seu Plano de Gerenciamento Integrado para poder ter instrumentos de ação legitimados. As políticas ainda não estão propensas a acompanhar a expansão de mercados e reduzem as trocas ao interesse material. Elas precisam de diagnósticos mais precisos sobre os hábitos de consumo, as condiçóes regionais de produção, circulação e consumo e acessibilidade aos bens e serviços.

As contradiçóes estão nas relaçóes de concorrência e de poder entre as pessoas e suas posiçôes de domínio no território e o uso que os atores fazem das coisas. Para o estabelecimento de novas territorialidades, é preciso que criar relações mais estreitas entre esta tríade de geradores de resíduos - indústria, comércio e governo - no plano simbólico (educação ambiental), material (produtos) e estrutural (aterros sanitários). 


\section{CONCLUSÓES}

O objetivo deste estudo foi alcançado na medida em que se constatou que as dinâmicas territoriais dos resíduos eletroeletrônicos domiciliares acontecem num espaço social multifacetado em que os atores trabalham com o consentimento, com a desigualdade, e com a dominação. Nem todos podem modelar o processo de coleta e disposição dos RSU, pois as condições materiais e o acesso às informações causam indesejáveis situaçôes de dependência.

Fazendo as distinções possíveis e necessárias, a todo momento se criam novas formas de satisfação das necessidades, e as significações mudam com a intensificação de fluxos e interdependências. As mudanças de hábitos de consumo construídas cotidianamente nas dimensóes vivenciadas acompanham o ritmo das técnicas, dos desejos e das perspectivas culturais. Enquanto isso, a produção de resíduos e os problemas ambientais crescem e os planos de gerenciamento de RSU se tornam obsoletos.

São dez anos de PNRS. Tudo ainda é muito novo no cenário político, sobretudo pela sazonalidade dos mandatos. Em cada reorganização do território há processos de inclusão e de exclusão de prioridades e autoridades. Considerando a essencialidade material da política, ainda há aqueles que pensam como dispender os recursos e aqueles que vão executar as açóes. Esta separação enfraquece os atores, os processos, e a política da coleta seletiva e dos demais resíduos. Não há uma organização política e institucional para dar suporte à PNRS no município de Matinhos- $\mathrm{PR}$, e nem às normas regulamentares da atividade.

Esta afirmação pode ser constatada pela observação de sua paisagem urbana. Os parques acolhem resíduos, as praias estão com suas "lixeirinhas" abarrotadas, as caçambas estão em péssimo estado de conservação; não há separação de materiais orgânicos e recicláveis nas caçambas porque os catadores coletam em ambos os contêineres, e a área em frente Secretaria de Meio Ambiente está repleta de resíduos da construção civil. Nesta desorganização, a maior parte de resíduos acaba tendo como destino final o aterro CIAS. Isto inclui materiais recicláveis, eletroeletrônicos, pneus, isopor, colchóes, madeiras, dentre outros. A forma pretensamente exclusivista como os detentores do poder local atuam aumenta a grandeza dos problemas, como é o caso do barracão construído para a ANCRESMAT, que ora encontra-se ocupado pela Fukuoka. O que parecia ser soluçáo se tornou outra dificuldade.

\section{AGRADECIMENTOS}

Agradecimentos especial ao Instituto Federal do Paraná, campus Paranaguá; Programa de Pós-Graduação em Tecnologia e Sociedade (PPGTE-UTFPR); aos catadores e catadoras das Associações AMAGEM, ANCRESMAT e Associação Fukuoka Instituto; e Secretaria Municipal de Meio Ambiente de Matinhos-PR. 


\section{REFERÊNCIAS}

ASSOCIAÇÃO FUKUOKA INSTITUTO. Disponível em: < http://www.afukuoka.com. br/2/site/>. Acesso em: 9 abr. 2020.

BRASIL. IBGE. Paraná. Matinhos. 2020b. Disponível em: <https://cidades.ibge.gov.br/ brasil/pr/matinhos/panorama>. Acesso em: 9 abr. 2020.

BRASIL. Ministério do Meio Ambiente. Agenda 21 Global. 1992. Disponível em: $<$ https://www.mma.gov.br/responsabilidade-socioambiental/agenda-21/agenda-21global>. Acesso em: 7 abr. 2020.

BRASIL. Lei Federal n. 12.305 de 2 de agosto de 2010. Institui a Política Nacional de Resíduos Sólidos; altera a Lei no 9.605, de 12 de fevereiro de 1998; e dá outras providências. Disponível em: <http://www.planalto.gov.br/ccivil_03/_ato20072010/2010/lei/112305.htm. Acesso em: 7 abr. 2020.

BRASIL. Decreto n. 10.240 de 12 de fevereiro de 2020. Regulamenta o inciso VI do caput do art. 33 e o art. 56 da Lei no 12.305, de 2 de agosto de 2010, e complementa o Decreto n. 9.177, de 23 de outubro de 2017, quanto à implementação de sistema de logística reversa de produtos eletroeletrônicos e seus componentes de uso doméstico. 2020a. Disponível em: <https://www.legisweb.com.br/legislacao/?id=389786>. Acesso em: 9 abr. 2020.

BRASIL. Decreto n. 9.177, de 23 de outubro de 2017. Regulamenta o art. 33 da Lei no 12.305, de 2 de agosto de 2010, que institui a Política Nacional de Resíduos Sólidos, e complementa os art. 16 e art. 17 do Decreto no 7.404, de 23 de dezembro de 2010 e dá outras providências. Disponível em: < http://www.planalto.gov.br/ccivil_03/_Ato20152018/2017/Decreto/D9177.htm>. Acesso em: 9 abr. 2020.

CÂMARA MUNICIPAL DE MATINHOS. Lei n. 1098, de 13 de abril 2007. Institui a Política Municipal de Resíduos Sólidos no município de Matinhos, seus princípios objetivos e instrumentos, e estabelece diretrizes e normas de ordem pública e interesse social para o gerenciamento dos diferentes tipos de resíduos sólidos. Disponível em: < https://www.camaramatinhos.pr.gov.br>. Acesso em: 9 abr. 2020.

CANCLINI, N. G. Consumidores e cidadáos. Conflitos multiculturais da globalização. Rio de Janeiro, Editora UFRJ, 2015.

CANDIOTTO, L. Z. P. (orgs.). Desenvolvimento territorial e agroecologia. São Paulo: Expressão Popular, 2008, p. 15-33.

\section{CERRI, Alberto. Quais os impactos ambientais dos metais pesados presentes nos} eletrônicos? ECYCLE. Disponível em: <https://www.ecycle.com.br/428-metais-pesadosimpactos >. Acesso em: 10 abr. 2020. 
CHIZZOTTI, A. Pesquisa qualitativa em Ciências Humanas e Sociais. 3. ed. Petrópolis: Vozes, 2006.

DEPOIMENTOS 1, 2, 3. 4. 5. Entrevistas concedidas aos autores. Matinhos, 2019.

DULLIUS, A.; SILVA, M. C. A região do Lagamar: fronteiras abertas para o re/ ordenamento territorial Revista Eletrônica Expediçóos: Teoria da História e Historiografia, v. 7, p. 84-97, 2017.

DULLIUS, A., SILVA, M. C., DIAS, M. S. L. Coleta e disposição de resíduos sólidos na cidade de Matinhos-PR. In: II Simpósio Brasileiro de Desenvolvimento Territorial Sustentável (II SBDTS), 2017, Matinhos. Anais do II Simpósio Brasileiro de

Desenvolvimento Territorial Sustentável (II SBDTS). Matinhos: Universidade Federal do Paraná. v. 1. p. 1482-1491, 2018.

DULLIUS, A. Dinâmicas territoriais de apropriação e concessão de tutoria para a gestáo de resíduos recicláveis por associaçóes de catadores em Matinhos-PR. $253 \mathrm{f}$. 2020. Tese (Doutorado em Tecnologia e Sociedade) - Universidade Tecnológica Federal do Paraná. Campus Curitiba, 2020.

FLICK, Uwe. Introduçáo à pesquisa qualitativa. 3a ed. Porto Alegre: Artmed, 2009.

GEHLEN, I; RIEELLA. A. Dinâmicas territoriais e desenvolvimento sustentável. Sociologias, Porto Alegre, n. 11, p. 20-26, 2004.

HAESBAERT, R. O mito da desterritorialização: do "fim dos territórios" a Multiterritorialidade. Bertrand Brasil: Porto Alegre, 2004.

JACOBI, P. Impactos socioambientais urbanos - do risco à busca pela sustentabilidade. MENDONÇA, F. (org). Impactos socioambientais urbanos. Curitiba, Editora UFPR, 2004, p. 169-184.

PARQUE NACIONAL DE SAINT-HILAIRE/SERRA DA PRATA. Lixo eletrônico, delete este perigo. 2019. Disponível em: <https://parnasainthilairelange.wordpress. com/2019/08/23/lixo-eletronico-delete-este-perigo/>. Acesso em: 12 mar. 2020.

PREFEITURA MUNICIPAL DE MATINHOS. Secretaria Municipal do Meio Ambiente. Plano de Gerenciamento Integrado dos Resíduos Sólidos. 2012. Disponível em: < http://ti.matinhos.pr.gov.br:2020/tce/controladoria/Plano_Gerenciamento_ Integrado_Residuos_Solidos-pt-2.pdf>. Acesso em: 9 abr 2020.

RAFFESTIN, C. Por uma geografia do poder. São Paulo: Ática, 1993.

RODRIGUES, A. M. Produçáo e consumo do e no espaço: Problemática ambiental urbana. São Paulo: Hucitec, 1998. 
SANTOS, M. O dinheiro e o território. In: Revista Geo Graphia. Ano 1, n.1. 1999, p. 7-13.

SANTOS, M. Da totalidade ao lugar. São Paulo: Editora da Universidade de São Paulo, 2004.

SANTOS, M. A urbanização brasileira. São Paulo: Editora da Universidade de São Paulo, 2005.

SAQUET, M.A.; SPOSITO, E.S. Território, territorialidade e desenvolvimento: diferentes perspectivas no nível internacional e no Brasil (15-33) In: ALVES, A. F; CARRIJO, B. R; 